\title{
GENDER, LEADERSHIP STYLES AND ADMINISTRA- TIVE EFFECTIVENESS OF PRINCIPALS IN CROSS RIVER STATE
}

ESTHER S. UKO

(Received 25 September 2001; Revision accepted 12 November 2001).

\section{ABSTRACT}

The aim of this study was to investigate the influence of gender on leadership styles and administrative effectiveness of secondary school principals in selected schools in Cross River State. In pursuance of this study, two hypothesis were formulated. Two sets of questionnaires, Principal's Self-Evaluation Questionnaire (PSEQ) and Principals' Administrative Effectiveness Questionnaire (PAEQ) were developed' and used to collect data from one thousand secondary school teachers and two hundred principals and vice principals randomly selected from one hundred secondary schools in Cross River State. The data collected were subjected to statistical analysis using independent t-test and chi-square analysis. The following results merged: There was a significant gender influence on principal's administrative effectiven:ss in tems of human relations. There was no significant influence of gender on principals' leadership styles effectiveness

KeyWords: Empirical Research, Gender. Leadership Slyles, Administrative Effectiveness, School Principals.

\section{INTROÉUCTION AND BACKGROUND}

The position of the principal is very important in the organization of the secondary school system. Apart from directing the affairs of the school, the principal is responsible for efficient utilization of human and material resources and coordination towards realization of the organizational goals. Being at the apex of the secondary school administration, the success of the school in implementing the educational programmes depends largely on the principal, in spite of gender. It is a known fact that education contributes an important premise in the development of the human resources needed for the nation's productive sector. However. the educational systems have been accused by parents and the general public of not being capable of maintaining maximum use of available resources and providing effective administrative arrangement for meaningful educational development. According to Adesina (1981), the level of ineffectiveness in the administration of the school system is associated with the rampant cases of students' unrest, poor examination results, examinations leakages, drug addiction, vandalism, among others.

There is an underlying evidence that the effectiveness of the school is closely related to the administrative role of the principal. To most parents and teachers, the issue of administrative effectiveriess in any secondary school is a matter of the person occupying the office of the school principal. This has generated a lot of controversy

as to who can be a more effective school administrator, the male or female principal.

Women are influenced by the societal belief that they occupy subordinate pcsitions, are poor supervisors, too emotional, take things personally and cannot cope with disciplinary 
problems arising from students' militancy. This however has led to non-recognition or acceptability of women in certain key positions in government, -industry and academics as men are always given preferential appointment over them. This, according to Awe (1990) has arisen as a result of the cultural stereotyping of males and females by different communities and cultures

However, the task of administering the secondary school system involves a number of factors. These include: the application of requisite skills in harnessing and utilizing available resources, ability to effectively coordinate the school, setting relevant goals and objectives, formulating plans and defining the jobs to be done by each unit. The attainment of each task therefore requires application of effective leadership styles, the stereolype effects notwithstanding.

Empirical findings according to Igwe (1990) have shown that within the Nigerian educational system, the percentage of male principals has exceeded that of their female counterparts despite the fact that women constitute a large proportion of the teaching force. Studies conducted by scholars like Atkinson (1981) and Ezeigbo (1996) have supported that appointment into principalship positions might at times be a matter of preference resulting in men being more frequently appointed into managerial positions in secondary schools than women. This results in women being highly discriminated against on matters of administrative appointments. Reasons advanced for the discriminatory treatment according to Atkinson (1921) include the followirig:
(1)
Women are seen to be passive and less self-assertive in nature.

Women are conformists and
submissive rather than
independent and dominant.

School Management according to Awe (1990) has been stereotyped as a masculine area. In a study conducted by Lasiele (1999) it was found out that women suffered discrimination in seeking executive appointments and that parents and communities preferred male principals to their female counterparts.

The assumption that men are better principals than women was previewed in studies conducted by Rinehart and Kols (1988), and Ezeigbo (1996). The result revealed that women ranked significantly ahead of men as democratic leaders and exhibited significantly more effective administrative practices than men. Also, female principals were perceived significantly higher than their male counterparts in terms of administrative effectiveness.

Dantiye and Garba (1991) identified some common features among Nigerian women which cut them out for managerial appointments to include tolerance and endurance, high need for association, frankness in matters considered serious, persuasiveness, stubbornness to a belief, emotional stability, consideration and fairness. Amali (1991) found out that there was no justification in the argument that males exhibit appropriate leadership styles than females in their executive appointments

Leadership is an important human component in an organized system which is developed through traning and exhibited through interaction with members of the group who voluntarily accept the responsibility to work for the achievement of common goals (Okojie, 1990). Ejiogu (1985) in his study averred that irrespective of sex the relationship between the group members and their leader is critical to the leadership process.

Teachers, however may be committed to their jobs and contribute to the success of the school in a favourable social climate characterized by democratic leadership. In support of this, Okojie (1990) found out that leadership styles adopted by school principals always influence their subordinates' attitude and subsequent performance in achieving
organizational goals, in spite of sex. Also, students' perception of a principal's leadership style could affect the type of attitude in which they exhibit within the school. Hence students' positive attitude towards the school and learning resulting from their perception of the principal's leadership styles would always influence the tone of the school and its academic performance. 


\section{THEORETICAL PERSPECTIVES AND HYPOTHESES}

Social scientists and management theorists have carried out extensive studies in the field of leadership. According to Nwachukwu (1988), the factors which affect leadership in an organization include the leader's behaviour, leadership qualities, behaviour of the members, environmental factors, structure of the organization, performed tasks and members expectations from their leader. Dantiye and Garba (1991) are of the opinion that for administrative effectiveness, a school principal should adopt reasonable leadership style so as to endear both the teachers and studenis to himself, since his leadership style has a direct effect on the social climate of the school

Thus, an effective management process is a function of the leadership styles of the person at the head of an organization. Leadership style therefore has direct influence on the administrative effectiveness of the school system. For effectiveness, the leadership style should be both task and human oriented, that is, showing concern for people and concern for production. Concern for people refer primarily to sound and warm interpersonal relations, self-esteem and the personal worth of members. Concern for production denotes successful accomplishment of organizational tasks.

Administrative effectiveness considers two adjuncts of the administrator's functions, namely: administration and effectiveness. Administration deals with planning activities which include describing the tasks to be performed in order to attain set goals, making subordinates perform efficiently within defined limits, enforcing the rules and regulations of the organization and drawing on the expertise of the principal to reach appropriate decisions. Effectiveness on the other hand results from efficient utilization of available resources to achieve the desired objectives of the organization.

Administrative effectiveness therefore, can be defined as the means of attaining the goals and objectives of an organization and can be easured in terms of how the principal can ntrol, motivate and inspire his subordinates towards the successful completion of assigned tasks.

To find out the influence of gender on leadership style and administrative effectiveness, the following hypotheses were tested.

\section{HYPOTHESES}

The two hypotheses used in the study are stated below in the "null" form. The raw scores for each variable were summed up from the subjects' responses and the mean $(x)$ and standard deviation (SD) were computed

Hypothesis I:

The principal's administrative effectiveness in terms of human relations is not significantly influenced by gender.

Hypothesis II:

There is no significant influence of the sex of the principal on his or her leadership style.

\section{Purpose of the Study:}

The purpose of the study was to find out if gender has any significant influence on the administrative effectiveness and leadership styles of secondary school principals in Cross River State.

\section{METHODOLOGY}

\section{Research Area:}

The study was conducted in cume selected secondary schools in Cross River State. it covered the four educational zones of the State. namely; Calabar, Ugep; Ikom and Ogoja

\section{Population of the Study:}

The population of the study included all the principals, vice principals, and teachers in the selected schools. The principals were used in the study because effective administration in the secondary school system rests on their shoulders. The vice principals by virtue of their position in the secondary school system take up the mantle of leadership when the principals are not around. They share in the responsibility of the day to day administration of the school 
organisation. Teachers used in the study are those who have worked at least three years. the assumption being that having spent some lime with the said administrators. they would be in a better position to validly assess the administrative effectiveness of their principals and vice principals.

The population of the study was made up of two thousand, seven hundred and fifty two (2.752) teachers and four hundred and thirty nine (439) principals and vice principals.

\section{Sample and sampling procedure:}

The total sample used for the study was one thousand i 1 UOD) teachers and two hundred (200) principals and vice principals, randomly selected from one hundred (100) secondary schools in Cross River State.

To obtain an adequate representative sample of principals and teachers from the selected schools, the stratified random sampling technique was used in drawing up the sample of schools to be involved in the study. A valid list of secondary schools in the State was obtained from the Post Primary Schools Management Board (PPSMB). Calabar. In order to allow for representativeness of the sample, the schools were stratified on the basis of educational zones, location and school type. Through the simple random method, 100 secondary schools were selected from 145 secondary schools. A breakdown of the 100 secondary schools selected revealed that 10 schools were single sex boys, another 10 were single sex girls, while 80 schools were coeducational. For each of the sampled, schools, five teachers were used to assess the principals, while the other five were used to assess the vice principals (mostly the longest staying).

\section{Instrumentation:}

Two different types of questionnaires were constructed and used for the study. The Principal's Self-Evaluation Questionnaire (PSEQ) was designed to obtain information from the principals while the Principals' Administrative Effectiveness Questionnaire (PAEQ) was designed for the teachers to assess the effectiveness of their principals in terms of human relations.

Validity:

The instruments were scrutinised hy an expert in test and measurement and two experts in administration to ascertain the instruments' face validity. In all cases, the items on the instruments were judged to a large extent unambiguous and relevant to administrative effectiveness of school principals.

\section{Reliability:}

The reliability of the instruments was obtained through a test-retest method. Validated instruments were administered to 30 principals and 15 teachers, respectively. The data obtained were coded and subjected to statistical analysis using the Pearson Product Moment Correlational Analysis and independent t-test. Estimates of the reliability coefficient for both principals and teachers questionnaires are as shown in Table 1.

\section{Data Collection Procedure:}

The questionnaires are administered to principals and teachers in the selected schools.

TABLE I: Test Re'est Retiability estimate of the measure of administrative effectiveness

\begin{tabular}{|c|c|c|c|c|c|}
\hline Variables & $\begin{array}{l}\text { No. of } \\
\text { Itcmis }\end{array}$ & Testing & $T$ & SD & $Y$ \\
\hline \multirow{2}{*}{ Hluman Relations } & \multirow{2}{*}{8} & $1^{s t}$ & 30.03 & 4.79 & \multirow{2}{*}{0.83} \\
\hline & & $2^{m+1}$ & $32.4 \hat{3}$ & 5.23 & \\
\hline \multirow{2}{*}{ Leadership Style } & & $1^{\text {st }}$ & 29.85 & 4.28 & \multirow{2}{*}{0.93} \\
\hline & & $2^{m d l}$ & 31.09 & 4.30 & \\
\hline
\end{tabular}


Permission was obtained from the principals for teachers to participate in the study. Appeal was also made to the principals and vice principals to fill the questionnaires individually. To assist the researcher, co-ordinators were appointed for each of the schools for effective administration of all questionnaires given out. A total of 1,200 questionnaires were correctly filled and retrieved, giving a relurn rate of $100 \%$.

\section{PESULTS AND INTERPRETATION:}

\section{Hypothesis I:}

Using the independent t-test analysis, the hypothesis which states that the principal's administrative effectiveness in terms of human relations is not significantly influenced by gender was tested. The mean effectiveness of the male and female principals in human relations were computed. The result of the analysis is presented in Table 2.

The result of the analysis reveals a significant $t-$ value of 5.51 at .05 level of significance with 198 degrees of freedom. This was found to be far above the critical t-value of 1.98. Consequent upon this finding, the null hypothesis was rejected while the research hypothesis was retained. The result therefore means that there is a significant gender influence on principals' administrative effectiveness in terms of human relations.

Further observation of the result reveals that male principals have a higher mean level of human relations $(X-32.13)$ than their female counterparts. $(X-30.09)$. When the differences in means were compared statistically using the independent t-test analysis, it was found to be significant. This result means that male principals are more effective in maintaining human relations than their female counterparts.

\section{Hypo:hesis II:}

The null hypothesis posited that there is no significant influence of gender of the Principal on his/her leadership style. Using the chi-square statistical method. this hypothesis was tested. The result of the analysis is presented in Table 3.

The result shows that there is no significant influence of gender on principals' leadership style effectiveness. The nul! hypothesis, was retainec: because the calculated chi-square value of 1.26 was far below the critical $X^{2}$ value of 5.99 at .05 alpha level and with 2 degrces of freedom.

A breakdown analysis revealed that more male $(36.25 \%)$ than female $(27.50 \%)$ principals were autocratic in their learership style. On the other hand, more female $(55.00 \%)$ than male $(50.63 \%)$ principals were tronsactional in their leadership style. Also. mor. 'emale (17.50\%) than male (13.13\%) principals weie dtmocratic in their leadership style. The difference in styles of leadership however was not significant.

\section{DISCUSSION OF FINDINGS}

In Table 1. the result indicated that the male principals significantly performed better than their female counterparts in their human relations. The result revealed that male principals in Cross River State have more encouraging relationship

TABLE 2: An independent test analysis of gender differences in principals administrative elfectiveness in terms of human relations.

$\begin{array}{ccccc}\text { Gender } & 1 & \bar{x} & \text { SD } & 1 \\ \text { Male } & 160 & 32.13 & 1.85 & \\ \text { Female } & 40 & 30.09 & 2.16 & 5.51 \\ \text { Total } & 200 & 31.73 & 2.41 & \end{array}$

* Sigrrificánt at .05 level, critical $!=1.98$ df -198 
TABLE 3 : Chi-square analy sis of influence of gender and principals' leadership style.

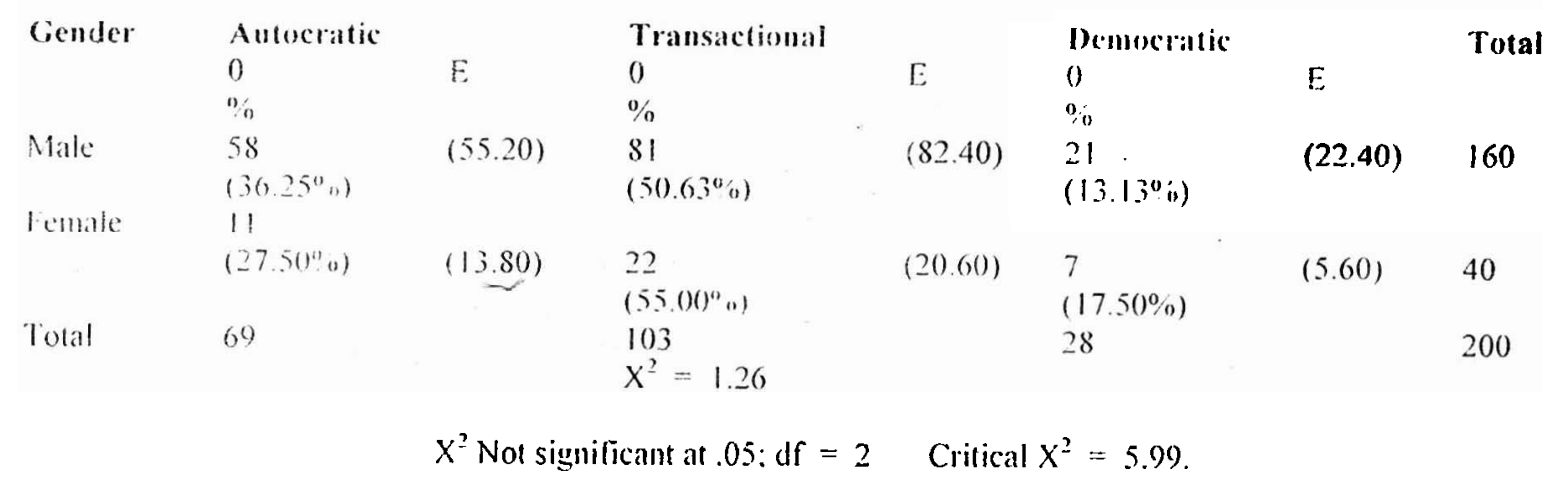

with their colleagues, visitors, and their employers than their female counterparts. They perceive their subordinates as their colleagues and therefore charted freely with them over any issue. Equally, they interacted freely with their employers, members of the community and the students without much inhibition.

The women were scored low on human relations because they were seen to be officious in their relationship with people including staff, students and visitors. Most women were equally weighed down

by the demands of their offices. For this reason they appeared not to be personally disposed at all times. Women were also scored lower than men because most of them when under pressure and intense provocation expressed extreme emotionality.

Men on the other hand were seen to be able to camouflage their emotional problems to the extent that they could easily handle difficult situations. The result of this finding is in agreement with the findings in a study conducted by Ediger (1991). He found out that women had low performance expectancies than men even when they have comparable abilities.

The result in Table 2 reflected a nonsignificant influence of gender on the administrative effectiveness of principals in terms of lead arship style. Leadership effectiveness was seen as a prerequisite to effective management. A study by Ezeigbo (1996) revealed that the leadership styles exhibited by school administrators have a significant influence on their subordinates' attitude and subsequent performance in achieving the organizational goals. Also, for seasoned executives there should be an underlying principle that the success of any organization depends on the leadership style demonstrated, irrespective of sex. The studies also confirmed that male and female. principals should adopt different styles as the situation demands. This supports the justification of the findings of this study that there was no significant influence of gender on the leadership styles of school principals.

A close examination of the result also revealed that more male than female principals were perceived by teachers to be more autocratic in their leadership styles, while more female than male principals were seen to be more democratic and transactional in their leadership styles. These results are consistent with the findings of Ejiogu (1985) and Awe (1990). Their findings revealed that leadership styles are dependent on the situation, innate abilities of the leader and the characteristics of those led. The findings further confirmed that female principals were more democratic and exhibited significantly more effective administrative practices than their male counterparts.

\section{CONCLUSION}

Within the limits of these research
findings, it can be concluded that the


affectiveness of the secondary school system in Cross River State is closely related to the administrative role of the principals, their gender notwithstanding. It is obvious from the results of the findings that both sexes demoristrated effectiveness within the limits of specific administrative indices within the school situation. This shows that there can be no. claim as to which of the sexes has absolute right to appointment into executive positions as secondary school administrators. From the fundings, male principals performed better in human relations than their female counterparts. On the other hand, female principals were seen to be more transactional and democratic in their leadership styles than their male counterpaits. Thele is therefore no justification to assent that men perform better than women as secondary school principals. Rather, the yardstick should be based on what index of administrative ineffectiveness is under consideration.

\section{RECOMMENDATIONS}

Based on the findings of this study. the following recommendations are made:

1. There should be no discrimination on the basis of gender in the appointment of secondary school principals. The selection of secondary school principals should be based on validated methods. This would ensure that only qualified and competent teachers are appointed to man the affairs of the secondary school system, irrespective of sex.

2. With the importance and powers accorded to the office of the secondary school principals, many teachers aspire to become principals. The practice of selecting secondary school principals on the basis of gender is therefore most unsatisfactory. It gives room for discrimination and inequality, thereby creating frustration and lack of job satisfaction to ambitious, devoted, conscientious and competent female teachers."

3 Both male and female principals should be Encouraged to be professionally committed to tileit work. This calls for the professionalization of in $=$ leaching profession.

$\therefore \quad$ Principals. irrespective of sex. should maintain a harmonious working relationship with the staff, students, visitors, the immediate community and education authorities. This will create a healthy atmosphere that permeates all aspects of the school and will bring out the best from all participants.

5. Both males and females principals should be exposed to refresher courses and workshops on modern management techniques, especially in human relations to enable them relate effectively with all arms of the school community.

\section{REFIRENCES}

Adesima. S. 1981. Intructuction to celucalional plamming. Ile-He: University of lfe Press I.id.

Amili. 1:.. 1991. Developing Nigerian women managers for the socio- economic transformation of Nigeria. Joumal of Manngement in Nigeria. 27 (6): $6.9 \%$

Akinson. J. W. (1981). Women in school administration. Review of Educational Research. Vol. 51 (3): 311 .. 343.

Awe. B., 1990. The role of women in management in the 90s. Jownal of Management in Nigeria. $26(6)$ : 9 .. 13.

Dantiye. N. I. And Garbil, M. A.. I991. Developing the management eapacities of the Nigerian women for higler nationat respunsibilities. Journal of Namagement in Nigerial. 27(6): 1315.

Fdiger, T. I. 1901. Problem solving and the school administrator. The progress of liducation 6 (3): 130 $-132$

Fiogu. A. M. 1985. Pan an principals' leadership

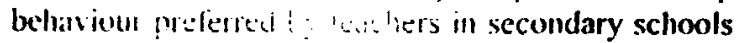
in Ligeos. Jumbal in iesticr Education. 1 (1): 77 86 .

lzeigho. A.. 1996. (iender is nes in Nigeria. A Feminine Perspective lages Visa Borohs Lid.

Igwe. S. O.. 1900) Prolewnal Handhook for Teachers Oweri Nen Shoun lublinhg Comman! Limited. 
Lasiele. Y. A., 1999. Women empowerment in Nigeria: problems. prospects and implications. Journal of Counselling in Nigeria. 17 (1): 1.32 - 137.

Nwachukwu, C. C.. 1988. Management theory and practice. Ibadan: African Publishers l.ıd.
Okojie. C. E.. 1990. Nigerian women ir public sector. Journal of Management :n Nigeria. 26 (6): $47-53$.

Rinelart. W. and Kols. A.. 1988: Women and development. Journal of Personuel Work. 2 ( I): 24. 